\title{
Study of Urothelial Neoplasm in Central India With Reference to WHO/ISUP Grading
}

\author{
Khare V, Jain VK, Tantuway $R$ \\ Dr Vivek Khare, Assistant Professor in Pathology, Dr Vivek Kumar Jain, Assistant Professor in Pathology, Dr Rajendra \\ Tantuway, Tutor in Pathology. All are affiliated with L N Medical College, Bhopal, India
}

Address for correspondence: Dr Vivek Khare, Email: drvivekkhare@rediffmail.com

\begin{abstract}
Introduction: Urothelial carcinoma is the most common bladder cancer, is often described as a polyclonal field change defect with frequent recurrence due to heightened potential for malignant transformation. Urothelial neoplasm runs the gamut from small benign neoplasm that may never recur to tumors of lower indeterminate malignant potential to lesions that invade the bladder wall and metastasize frequently. Hence histologic grading of these tumors to predict behavior has been subject of great debate as there is poor inter - observer reproducibility and no uniformity. Material and Methods: The present study was carried out in the Department of Pathology, L.N. Medical College, Bhopal, India. It was both a prospective and a retrospective study of 80 patients whose urinary bladder biopsy were studied. Result: 80 cases reported out of which 20 were transitional papilloma, 52 were cases of ransitional cell carcinoma and 8 cases were of squamous cell carcinoma. The majority of tumours are present in age group of 50-80 years. Discussion: Although World Health Organization classification system is most commonly used grading system but lack of detailed histological criteria motivated WHO and ISUP to publish a consensus classification for urothelial neoplasm of urinary bladder. The majority of the cases in this study belonged to the histologic grades of papillary carcinoma of low grade which corresponds to the WHO classification of transitional cell carcinoma grade II.
\end{abstract}

Key words: Transitional cell carcinoma, Urothelial neoplasm, WHO/ISUP grading

\section{Introduction}

Bladder cancer is a common urologic cancer that has the highest recurrence rate of any malignancy. According to a comprehensive analysis of 1476 radical cystoprostatectomy specimens, patients undergoing this procedure for bladder urothelial carcinoma commonly have incidental prostate cancers. ${ }^{1,2}$ In North America, South America, Europe, and Asia, the most common type

Manuscript received: $10^{\text {th }}$ Aug 2013

Reviewed: $16^{\text {th }}$ Aug 2013

Author Corrected: $30^{\text {th }}$ Aug 2013

Accepted for Publication: $23^{\text {rd }}$ Sep 2013 of urothelial tumor diagnosed is transitional (urothelial) cell carcinoma (TCC); it constitutes more than $90 \%$ of bladder cancers in those regions. TCC can arise anywhere in the urinary tract, including the renal pelvis, ureters, bladder, and urethra, but it is usually found in the urinary bladder. Carcinoma in situ (CIS) is frequently found in association with high-grade or extensive TCC. ${ }^{3}$ Squamous cell carcinoma (SCC) is the second most common cell type associated with bladder cancer in industrialized countries. In the United States, around 5\% of bladder cancers are 
$\mathrm{SCCs}^{4}$. Worldwide, however, SCC is the most common form of bladder cancer, accounting for $75 \%$ of cases in developing nations.

Approximately $2 \%$ of bladder cancers are adenocarcinomas. Nonurothelial primary bladder tumors are extremely rare and may include small cell carcinoma, carcinosarcoma, primary lymphoma, and sarcoma. Small cell carcinoma of the urinary bladder accounts for only 0.3 $0.7 \%$ of all bladder tumors. High-grade urothelial carcinomas can also show divergent histologic differentiation, such as squamous, glandular, neuroendocrine, and sarcomatous features ${ }^{5}$.

Clinical and pathologic data indicate that at least 3 different phenotypes, as follows, exist in urothelial carcinoma 4,6

- Low-grade proliferative lesions that develop into non muscle- invasive tumors; these account for approximately $80 \%$ of bladder cancers

- Highly proliferative invasive tumors with a propensity to metastasize

- CIS, which can penetrate the lamina propria and eventually progress

Divergent, yet interconnected and overlapping, molecular pathways are likely responsible for the development of noninvasive and invasive bladder tumors. Somatic mutations in fibroblast growth receptor 3 (FGFR-3) and tumor protein p53 (TP53) in tumor cells appear to be important early molecular events in the noninvasive and invasive pathways, respectively. FGFR-3, Ras, and PIK3CA mutations occur with high frequency in noninvasive tumors, leading to upregulation of Akt and mitogen-activated protein kinase $(\mathrm{MAPK})^{7,8}$. Loss of heterozygosity $(\mathrm{LOH})$ on chromosome 9 is among the most frequent genetic alterations in bladder tumors and is

considered an early event ${ }^{9}$. Large numbers of genomic changes have been detected using karyotyping and comparative genomic hybridization $(\mathrm{CGH})$ analysis in urothelial carcinoma. Numerically common are losses of $2 \mathrm{q}, 5 \mathrm{q}, 8 \mathrm{p}, 9 \mathrm{p}, 10 \mathrm{q}, 18 \mathrm{q}$, and Y. Gains of 1q, 5p, 8q, and
$17 \mathrm{q}$ are frequently present, and high-level amplifications can be found; however, the target genes in the regions of amplifications have not been conclusively identified. ${ }^{10}$

Up to $80 \%$ of bladder cancer cases are associated with environmental exposure. Tobacco use is by far the most common cause of bladder cancer in the United States and is increasing in importance in some developing countries. Smoking duration and intensity are directly related to increased risk. ${ }^{11,12,13}$. Risk of developing bladder carcinoma is 2-6 times greater in smokers than in nonsmokers. This risk appears to be similar between men and women ${ }^{14}$. Nitrosamine, 2-naphthylamine, and 4-aminobiphenyl are possible carcinogenic agents found in cigarette smoke.

Occupational exposure to aromatic amines or aniline dyes is presumed to be the cause of bladder cancer in up to $25 \%$ of cases. Numerous occupations associated with diesel exhaust, petroleum products, and solvents (eg. auto work, truck driving, plumbing, leather and apparel work, rubber and metal work) have also been associated with an increased risk of bladder cancer. People living in urban areas are also more likely to develop bladder cancer. The etiology in these cases is thought to be multifactorial, potentially involving exposure to numerous carcinogens. ${ }^{15}$

In many developing countries, particularly in the Middle East, Schistosoma haematobium infection causes most cases of bladder SCC. In a study from Egypt, $82 \%$ of patients with bladder carcinoma harbored $\mathrm{S}$ haematobium eggs in the bladder wall. In egg-positive patients, the tumor tended to develop at a younger age (with SCC predominant) than it did in egg-negative persons. A higher degree of adenocarcinoma has also been reported in schistosomal-associated bladder carcinomas. ${ }^{16}$

\section{Material and Methods}

The present study was carried out in the Department of Pathology, L.N. Medical College, Bhopal. It was both a prospective and a retrospective study of 80 patients whose urinary bladder biopsy were studied. For retrospective study, histopathology records of patients were studied up 
to January 2011. Diagnosed cases of urinary bladder carcinoma were selected.

The paraffin blocks of these cases were retrieved. For prospective study urinary Bladder Biopsy, partial and total

\section{Results}

Table No. 1: Number of Cases of Various Urinary Bladder neoplasm

\begin{tabular}{|c|c|c|}
\hline & Number of cases & Percentage \\
\hline Transitional papilloma & 20 & $25 \%$ \\
\hline Transitional cell carcinoma & 52 & $65 \%$ \\
\hline Squamous cell carcinoma & 8 & $10 \%$ \\
\hline
\end{tabular}

As per Table 180 cases of urinary bladder tumors were studied, out of which $25 \%$ were of Benign transitional cell papilloma, $65 \%$ were of transitional cell carcinoma and $10 \%$ were of squamous cell carcinoma.

Table No. 2: Distribution of urothelial neoplasm (WHO grading)

\begin{tabular}{|c|c|c|}
\hline Type of Lesion & Number of cases & Percentage \\
\hline Papilloma & 20 & $27 \%$ \\
\hline Transitional cell carcinoma Grade I & 4 & $5.5 \%$ \\
\hline Transitional cell carcinoma Grade II & 26 & $36.1 \%$ \\
\hline Transitional cell carcinoma Grade III & 22 & $30.5 \%$ \\
\hline
\end{tabular}

On classification as per WHO grading Papilloma were present in 27\%. Higher grade transitional cell carcinoma was more common then lower grade carcinoma.

Table No. 3: Age distribution of patients with urothelial neoplasm

\begin{tabular}{|c|c|c|}
\hline Age Distribution (Years) & Number of cases & Percentage \\
\hline $\mathbf{3 1 - 4 0}$ years & 14 & $20 \%$ \\
\hline $\mathbf{4 1 - 5 0}$ years & 16 & $32 \%$ \\
\hline $\mathbf{5 1 - 6 0}$ years & 26 & $10 \%$ \\
\hline $\mathbf{6 1 - 7 0}$ years & 8 & $20 \%$ \\
\hline $\mathbf{7 1 - 8 0}$ years & 16 & $20 \%$ \\
\hline
\end{tabular}


Table No. 4: Sex distribution of patients with urothelial neoplasm

\begin{tabular}{|c|c|c|}
\hline Sex & Number of cases & Percentage \\
\hline Male & 72 & $90 \%$ \\
\hline Female & 8 & $10 \%$ \\
\hline
\end{tabular}

As per Table no. 3 and 4, majority of cases of urothelial neoplasm (32\%) were in between the age of 51-60 years and majority cases $(90 \%)$ were seen in male gender with only $10 \%$ in females.

Table No. 5: Type of tumor (WHO/ISUP grading)

\begin{tabular}{|c|c|c|}
\hline Type of Lesion & Number of cases & Percentage \\
\hline Papilloma & 20 & $27 \%$ \\
\hline Papillary neoplasm of low malignant potential & 4 & $5.5 \%$ \\
\hline Papillary carcinoma low grade & 26 & $36.11 \%$ \\
\hline Papillary carcinoma high grade & 22 & $30.5 \%$ \\
\hline
\end{tabular}

As per table no. 5 maximum number of cases of urothelial neoplasm studied according to WHO / ISUP consensus classification was of papillary carcinoma low grade.

\section{Discussion}

The progression of bladder cancer is dependent on the degree of anaplasia of tumour cells defined as increased cellularity, nuclear crowding, disturbance of cellular polarity, failure of differentiation from the base to the surface, pleomorphism, irregularity in cell size, variations of shape and chromatic pattern of the nuclei, displaced or abnormal mitotic figures and giant cells. This was the basis for the WHO Classification system proposing three tiered system of grade 1,2 and 3.

Though well accepted by pathologist, urologist and oncologist, however, lacks detailed histological criteria hence recently described WHO / ISUP consensus flat and papillary pre invasive neoplasm in order to improve the reproducibility of grading among pathologists and to correlate grades with better defined prognosis. As per Indian cancer registry data in men, urothelial carcinoma is the ninth most common cancer accounting for $3.9 \%$ of all cancer (Kurkure, 2001) ${ }^{17}$. Men are effected more often than women (3-4:1) (Reutor

VE, 2004) ${ }^{18}$. According to WHO (2004)/ISUP, Urothelial tumors may be of flat or papillary on the basis of the pattern of growth of the intraepithelial lesion, which may lead to invasive Urothelial carcinoma. Papillary tumors recognised in this classification are, Urothelial Papilloma, Urothelial neoplasm of low malignant potential, Papillary urothelial carcinoma low grade and Papillary urothelial carcinoma, high grade.

The higher incidence of urothelial tumors in male than in female is probably related to difference in smoking habits and occupational exposure (Gupta et al., 2009) ${ }^{19}$. Low grade tumors can be invasive but significantly lower than high grade papillary carcinoma (Grignon, 2009) ${ }^{20}$. Patholgical stage is the most important determinant of prognosis and treatment (Cheng et al). ${ }^{21}$

Available online at: www.ijmrr.in 180 | P a g e


The majority of the cases of transitional cell carcinoma in the present study were between $50-80$ years. This corresponds to the study of Jordan and Murphy et al $(1987)^{22}$.This is similar to other study which showed that $80.6 \%$ presents older than 50 years (Al-Bazzaz, 2009) ${ }^{23}$. Younger patients frequently present with lower grade and lower stage tumors than their elder counter parts (Wan, 1989) ${ }^{24}$. Incidence of bladder cancer increases with age with median age at diagnosis of around 70 years (Lynch \& Cohen, 1995 $)^{25}$. The median age was 60 years old in our study, similar to a study in India (Gupta et al., 2009). ${ }^{19}$ Males (90\%) are involved more frequently than females. This corresponds to the study of Jorden \& Murphy et al $(1987)^{22}$. The male-female ratio in different parts of the world is varied.

In the present study most of the urothelial neoplasm $36.11 \%$ belonged to the histologic grade of papillary carcinoma of low grade according to WHO / ISUP Classification (1998).

Similar findings was also reported by Ahmed et $\mathrm{al}^{22}$ where $44 \%$ were low grade and $29.5 \%$ were high grade. However this does not correlate with study of Jordon and Murphy et $\mathrm{al}^{22}$ where $12.7 \%$ of the cases fall in grade 2 according to WHO classification.

In the present study invasive neoplasm (high grade) was constitute $30.5 \%$ of total cases. Result was similar to study by Ahmed et al $(37.6 \%)^{26}$. All the cases of this group of invasive neoplasm showed both nuclear and architectural features of high grade papillary neoplasm. Pathologic grade and muscle invasion are the most valuable prognostic predictors of survival.

This is supported by Blaveri et $\mathrm{al}^{27}$, who evaluated the association between genomic instability and muscle invasive tumours and found that worse outcome is associated with muscle invasive tumors. Eight cases of squamous cell carcinoma were reported, which were associated with chronic irritation in bladder due to catheterization and stone and parasites due to bilharziasis.

\section{Conclusion}

In our study majority of urinary bladder tumours were present in age group of 50-80 years, though it can occur in younger age group also. The maximum cases were seen in males and correspond to low grade urothelial carcinoma. Urothelial neoplasm runs the gamut from small benign neoplasm that may never recur to tumors of lower indeterminate malignant potential to lesions that invade the bladder wall and metastasize frequently.

Hence histologic grading of these tumors to predict behavior has been subject of great debate as there is poor inter- observer reproducibility and no uniformity. Thus a reliable grading system and universally accepted classification should be used effectively by Pathologist, Urologist and Oncologist.

Although World Health Organization classification system is most commonly used grading system but lack of detailed histological criteria motivated WHO and ISUP to publish a consensus classification for urothelial neoplasm of urinary bladder.

Thus it is concluded that the recently proposed WHO / ISUP grading system defines more accurately grades in papillary urothelial neoplasm taking in account of both nuclear and architectural features.

\section{Funding: Nil}

\section{Conflict of interest: Nil}

\section{Permission from IRB: Yes}

\section{References}

1. Harding A. Prostate often involved in bladder cancer. Medscape Medical News [serial online]. June 4, 2013; Accessed June 17, 2013. Available at http://www.medscape.com/viewarticle/805284.

2. Bruins HM, Djaladat H, Ahmadi H, Sherrod A, Cai J, Miranda G, Skinner EC, Daneshmand S. Incidental cancer of the prostate in patients with bladder urothelial 
carcinoma: comprehensive analysis of 1476 radical cystoprostatectomy specimens. J Urol. May 232013.

3. Novis DA, Zarbo RJ, Valenstein PA. Diagnostic uncertainty expressed in prostate needle biopsies: a College of American Pathologists Q-probes study of 15753 prostate needle biopsies in 332 institutions. Arch Pathol Lab Med. 1999 Aug;123(8):687-92.

4. Escudero DO, Shirodkar SP, Lokeshwar VB. Bladder Carcinogenesis and Molecular Pathways. Available at http://Cancer Drug Discovery and Development. Accessed 2011 23-41.

5. Kawabata K. Paraganglion of the prostate in a needle biopsy: a potential diagnostic pitfall. Arch Pathol Lab Med. 1997 May;121(5):515-6

6. Spruck $\mathrm{CH}$ 3rd, Ohneseit PF, Gonzalez-Zulueta M, Esrig D, Miyao N, Tsai YC, Lerner SP, Schmütte C, Yang AS, Cote R. Two molecular pathways to transitional cell carcinoma of the bladder. Cancer Res. 1994 Feb 1;54(3):784-8

7. Tomlinson DC, Baldo O, Harnden P, Knowles MA. FGFR3 protein expression and its relationship to mutation status and prognostic variables in bladder cancer. J Pathol. Sep 2007;213(1):91-8.

8. Eswarakumar VP, Lax I, Schlessinger J. Cellular signaling by fibroblast growth factor receptors. Cytokine Growth Factor Rev. Apr 2005;16(2):139-49..

9. Fadl-Elmula I. Chromosomal changes in uroepithelial carcinomas. Cell Chromosome. 2005 Aug 7;4:1

10. Knowles MA. Molecular subtypes of bladder cancer: Jekyll and Hyde or chalk and cheese?.Carcinogenesis. Mar 2006;27(3):361-73.

11. Brennan P, Bogillot O, Cordier S, Greiser E, Schill W, Vineis P, et al. Cigarette smoking and bladder cancer in men: a pooled analysis of 11 case-control studies. Int $\mathrm{J}$ Cancer. Apr 15 2000;86(2):289-94.

12. Fortuny J, Kogevinas M, Chang-Claude J, González

CA, Hours M, Jöckel KH, Bolm-Audorff U, Lynge E, 't
Mannetje A, Porru S, Ranft U, Serra C, Tzonou A,Wahrendorf J, Boffetta P. Tobacco, occupation and nontransitional-cell carcinoma of the bladder: an international case-control study. Int J Cancer. 1999 Jan 5;80(1):44-6

13. Kantor AF, Hartge P, Hoover RN, Fraumeni JF Jr. Epidemiological characteristics of squamous cell carcinoma and adenocarcinoma of the bladder. Cancer Res. 1988 Jul 1;48(13):3853-5.

14. Freedman ND, Silverman DT, Hollenbeck AR, Schatzkin A, Abnet CC. Association between smoking and risk of bladder cancer among men and women. JAMA. 2011 Aug 17;306(7):737-45

15. Stein JP, Skinner EC, Boyd SD, Skinner DG. Squamous cell carcinoma of the bladder associated with cyclophosphamide therapy for Wegener's granulomatosis: a report of 2 cases. J Urol. Mar 1993;149(3):588-9.

16. El-Bolkainy MN, Mokhtar NM, Ghoneim MA, Hussein $\mathrm{MH}$. The impact of schistosomiasis on the pathology of bladder carcinoma. Cancer. 1981 Dec 15;48(12):2643-8.

17. Kurkure AP. Cancer incidence and pattern in urban Maharastra. Consolidated report of the population based Cancer registries year 2001.cited on 9/10/2013 at http://www.karmayog.org/cancer/upload/11591/maharasht ra-report2001.pdf

18. Reutor VE. The Urothelial tract: renal pelvis ureter urinary bladder and urethra. In: Sternberg's diagnostic surgical pathology. 4thed. Philadelphia: Lippincott Williams and Wilkins, p. 2035-2074

19. Gupta P, Jain M, Kapoor R, Muruganandham K, Srivastava A, Mandhani A. Impact of age and gender on the clinicopathological characteristics of bladder cancer. ndian J Urol. 2009 Apr;25(2):207-10

20. Grignon DJ. The current classification of urothelial neoplasm. Mod Pathol. 2009 Jun;22 Suppl 2:S60-9

21. Cheng L, Montironi R, Davidson DD, Lopez-Beltran A. Staging and reporting of urothelial carcinoma of urinary bladder. Mod Pathol. 2009 Jun;22 Supp1 2:S70-95 
22. Jordan AM,Weing arten J. Murphy WM,:Transitional cell neoplasm of the urinary bladder,Can biologic potential be predicted from histologic grading? Cancer. 1987 Dec $1 ; 60(11): 2766-74$

23. Al-Bazzaz PH (2009). Stage of urinary bladder cancer at first presentation. Saudi J Kidney Dis Transpl. 2009 Jul;20(4):628-31

24. Wan J, Grosman HB (1989). Bladder carcinoma in patients 40 years or younger. Cancer. 1989 Jul $1 ; 64(1): 178-81$
25. Lynch CF, Cohen MB (1995). Urinary System. Cancer. 1995 Jan 1;75(1 Suppl):316-29

26. Ahmed Z, Muzaffer S, Khan M, Kayani N, Pervez S, Husseini AS, Hasan SH. Transitional cell carcinomas of the urinary bladder. A histopathological study. J Pak Med Assoc. 2002 Sep;52(9):396-8

27. Ahmed Z, Muzaffer S, Khan M, Kayani N, Pervez S, Husseini AS, Hasan SH. Bladder cancer stage and outcome by array-based comparative genomic hybridization. Clin Cancer Res, 11, 7012-22

\section{How to cite this article?}

Khare V, Jain VK, Tantuway R. Study of Urothelial Neoplasm in Central India With Reference To WHO/ISUP Grading. Int J Med Res Rev 2013;1(4):177-183. doi:10.17511/ijmrr.2013.i04.06 